\title{
Ultrastructure of Bacteroides capillus, B. buccae, B. pentosaceus, $B$. oris, $B$. oralis, $B$. veroralis, and Pentose Sugar-Fermenting Bacteroides sp. from Humans with Periapical Osteitis: Occurrence of External Proteinaceous Cell Wall Layer
}

\author{
MARKUS HAAPASALO,${ }^{1,2}$ KARI LOUNATMAA,${ }^{3 *}$ HELENA RANTA,${ }^{1,4}$ HAROUN SHAH, ${ }^{5}$ AND KARI RANTA ${ }^{1}$ \\ Department of Cariology, ${ }^{1}$ Department of Bacteriology and Immunology, ${ }^{2}$ Department of General Microbiology, and \\ Department of Electron Microscopy, ${ }^{3}$ University of Helsinki, and National Public Health Institute, ${ }^{4}$ SF-00280 Helsinki 28 , \\ Finland, and Department of Oral Microbiology, London Hospital Medical College, London E1 2AD, \\ United Kingdom ${ }^{5}$
}

\begin{abstract}
We describe the comparative ultrastructures of bile-sensitive Bacteroides species which were isolated from oral cavities and ferment xylose and arabinose. Reference strains Bacteroides buccae ATCC $33574^{\mathrm{T}}(\mathrm{T}=$ type strain), Bacteraides capillus ATCC $33690^{\mathrm{T}}$ and ATCC 33691, and Bacteroides pentosaceus $\mathrm{NP333}^{\mathrm{T}}$ and $\mathrm{WPH} 61$ and Bacteroides sp. strains ES42 and ES57 all had an extra surface layer (S-layer) outside the outer membrane. No S-layer was detected in Bacteroides oris ATCC $33573^{\mathrm{T}}$ and ATCC 27518 , Bacteroides oralis, Bacteroides veroralis, or Bacteroides sp. strains ES2759 and ES2834. The deoxyribonucleic acid guanine-plus-cytosine contents and both the malate dehydrogenase and glutamate dehydrogenase mobilities of the strains with an S-layer were identical. We suggest that the oral pentose-fermenting Bacteroides isolates with an S-layer may belong to the same species.
\end{abstract}

The taxonomy of saccharolytic Bacteroides species has been subjected to many changes (9). Until recently, Bacteroides ruminicola was recognized as the only bile-sensitive species capable of fermenting the pentose sugars xylose and arabinose. Several new species have now been proposed, including Bacteroides oris, Bacteroides pentosaceus, Bacteroides capillus, Bacteroides helcogenes (arabinose negative), Bacteroides suis, and Bacteroides buccae (1-3, 8). Recognition of $B$. ruminicola is based primarily on differences in deoxyribonucleic acid (DNA) base composition and DNA homology. However, the carbohydrate fermentation patterns and other biochemical characteristics of the newly proposed species are almost identical. B. capillus and $B$. pentosaceus strains do not liquefy gelatin, whereas most strains of $B$. oris and $B$. buccae do. The DNA base compositions (guanine-plus-cytosine contents) of $B$. capillus, $B$. buccae, and $B$. pentosaceus are of the same magnitude, 50 to $53 \mathrm{~mol} \%$, whereas that of $B$. oris is lower (42 to $46 \mathrm{~mol} \%$ ) (2, $3,8)$.

DNA homology studies have clearly demonstrated differences among $B$. oris, $B$. buccae, and $B$. ruminicola subsp. ruminicola $(2)$, but these studies have not yet been extended to include $B$. capillus and $B$. pentosaceus.

Biochemically, Bacteroides oralis and Bacteroides veroralis are closely related to the above-mentioned species, but they do not ferment pentose sugars. Exception for salicin and amygdalin fermentation by $B$. oralis and xylan fermentation by $B$. veroralis, these two species are biochemically indistinguishable (14).

Recently, Lai et al. (4) studied the ultrastructure of some anaerobic and microaerophilic bacteria and showed that morphological characteristics of biochemically related species may be useful in bacterial identification. Kornman and Holt found an extra layer (S-layer) external to the outer membrane of $B$. capillus, disorganized electron-opaque ma-

\footnotetext{
* Corresponding author.
}

terial surrounding this layer, and long hairlike projections emerging through it (3).

In this paper we describe the ultrastructure of biochemically similar reference strains of $B$. capillus, B. pentosaceus, $B$. buccae, and $B$. oris and eight clinical isolates of fermentative Bacteroides species obtained from dental root canal infections. Colonial characteristics, which may be useful for screening (as in the case of black-pigmented Bacteroides), are also reported.

\section{MATERIALS AND METHODS}

Strains. The reference strains used included $B$. capillus ATCC $33690^{\mathrm{T}}(\mathrm{T}=$ type strain) and ATCC 33691, B. buccae ATCC $33574^{\mathrm{T}}, B$. oris ATCC $33573^{\mathrm{T}}$ and ATCC 27518 (previously identified as $B$. ruminicola subsp. brevis) (2), and $B$. pentosaceus $\mathrm{NP}_{333^{\mathrm{T}}}$ and WPH61 (8). The eight clinical isolates obtained from human dental root canal infections included pentose-fermenting Bacteroides sp. strains ES42 and ES57 (7), B. oralis strains ES2734, ES2726, and ES2350, B. veroralis strain ES2745, and Bacteroides sp. strains ES2759 and ES2834, which biochemically are very similar to $B$. veroralis.

Isolation and culture. All of the strains from root canal infections were isolated as previously described (7). Pure cultures were kept in glycerin-milk at $-70^{\circ} \mathrm{C}$. B. pentosaceus strains were also preserved in glycerin-milk at $-70^{\circ} \mathrm{C}$ for this study. B. capillus, B. buccae, and $B$. oris strains were obtained as freeze-dried cultures from the American Type Culture Collection, Rockville, Md. All strains were grown on bacteriological agar no. 1 (Oxoid Ltd., Hampshire, England) supplemented with $5 \%$ horse blood, 5 $\mathrm{g}$ of yeast extract per liter, $0.5 \mathrm{mg}$ of menadione per liter, 500 $\mathrm{mg}$ of cysteine per liter, and $2 \mathrm{~g}$ of glucose per liter (MCG agar) in an anaerobic atmosphere (Gas Generating Kit-System; Oxoid); 3-day-old cultures after the fourth or fifth transfer were used for ultrastructural studies. The morphology and pigmentation of bacterial colonies were studied on MCG agar (containing horse blood) and on MCG agar 
TABLE 1. Phenotypic characteristics of B. capillus, B. buccae, $B$. pentosaceus, B. oris, Bacteroides sp. strains ES42 and ES57, $B$. oralis, B. veroralis, and Bacteroides sp. strains ES2759 and $\mathrm{ES} 2834^{a}$

\begin{tabular}{|c|c|c|c|c|c|}
\hline \multirow{2}{*}{ Organism } & \multicolumn{4}{|c|}{ Acid produced from: } & \multirow{2}{*}{$\begin{array}{c}\text { Gelatin } \\
\text { liquefactior }\end{array}$} \\
\hline & $\overline{\text { Xylose }}$ & Arabinose & Salicin & $\overline{\text { Cellobiose }}$ & \\
\hline $\begin{array}{l}\text { B. capillus } \\
\text { ATCC } 33690^{\mathrm{T}}\end{array}$ & $++^{b}$ & + & + & + & - \\
\hline $\begin{array}{l}\text { B. capillus } \\
\text { ATCC } 33691\end{array}$ & + & + & + & + & - \\
\hline $\begin{array}{l}\text { B. buccae } \\
\text { ATCC } 33574^{\mathrm{T}}\end{array}$ & + & + & + & + & + \\
\hline $\begin{array}{l}\text { B. pentosaceus } \\
\text { NP333 }^{\mathrm{T}}\end{array}$ & + & + & + & + & - \\
\hline $\begin{array}{l}\text { B. pentosaceus } \\
\text { WPH61 }\end{array}$ & + & + & + & + & - \\
\hline $\begin{array}{l}\text { B. oris } \\
\text { ATCC } 27518\end{array}$ & + & + & + & + & - \\
\hline $\begin{array}{l}\text { B. oris } \\
\text { ATCC } 33573^{\mathrm{T}}\end{array}$ & + & + & + & + & + \\
\hline $\begin{array}{l}\text { Bacteroides sp. } \\
\text { strain ES42 }\end{array}$ & + & + & t & + & $\mathrm{w}$ \\
\hline $\begin{array}{c}\text { Bacteroides sp. } \\
\text { strain ES57 }\end{array}$ & + & + & + & + & - \\
\hline $\begin{array}{l}\text { B. oralis } \\
\text { (3 strains) }\end{array}$ & - & - & + & + & - \\
\hline $\begin{array}{l}\text { B. veroralis } \\
\text { (1 strain) }\end{array}$ & - & - & - & + & - \\
\hline $\begin{array}{l}\text { Bacteroides sp. } \\
\text { strain ES2759 }\end{array}$ & - & - & - & - & - \\
\hline $\begin{array}{l}\text { Bacteroides sp. } \\
\text { strain ES2834 }\end{array}$ & - & - & - & - & - \\
\hline
\end{tabular}

${ }^{a}$ All strains produced acid ( $\mathrm{pH}$ less than 5.5) from glucose, lactose, mannose. raffinose, and saccharose. No strain produced acid from mannitol, melezitose, sorbitol, or trehalose. No strain produced indole or urease, and al strains hydrolyzed esculin and starch.

$b+$, Positive reaction; -, negative reaction; w, weak reaction.

supplemented with hemolyzed horse blood (HMCG agar). All strains were incubated for 2 weeks to detect pigmentation.

All strains were tested for the presence of catalase and urease, for indole production, for gelatin liquefaction (API$20 \mathrm{~A}$ system; API, Montalieu-Vercieu, France), and for hydrolysis of starch and esculin. Carbohydrate fermentation was tested by using the API-20A system. Susceptibility to kanamycin, vancomycin, and metronidazole was tested by the disk diffusion method (concentrations of 100,70 , and 16 $\mu \mathrm{g}$, respectively). In addition, the growth of all strains was assessed on Bacteroides bile-esculin agar.

Enzyme mobilities. Malate dehydrogenase $(\mathrm{MDH})$ and glutamate dehydrogenase (GDH) mobilities were measured as previously described (10). Cell-free extracts of $B$. capillus ATCC $33690^{\mathrm{T}}$ and ATCC 33691, B. buccae ATCC $33574^{\mathrm{T}}, B$. pentosaceus $\mathrm{NP} 333^{\mathrm{T}}$ and WPH61, and Bacteroides sp. strains ES42 and ES57 were electrophoresed and stained. Enzyme mobilities were measured relative to the enzymes of Bacteroides intermedius T588.

DNA base composition. DNA base compositions were determined for the same strains as enzyme mobilities. Cells grown in BM medium (11) to late exponential phase were harvested by centrifugation and washed twice in buffer containing $0.05 \mathrm{~mol}$ of tris(hydroxymethyl)aminomethane per liter, $0.05 \mathrm{~mol}$ of ethylenediamine tetraacetate per liter, and $0.01 \mathrm{~mol}$ of $\mathrm{NaCl}$ per liter ( $\mathrm{pH}$ 8.0) (TES buffer). Lysis of cells was carried out in TES buffer containing $50 \mu \mathrm{g}$ of proteinase K (E. Merck AG, Darmstadt, Germany) per ml and sodium dodecyl sulfate (final concentration, $1 \mathrm{mg} / \mathrm{ml}$ ) for
$15 \mathrm{~min}$ at $45^{\circ} \mathrm{C}$. The lysate was deproteinized and treated with ribonuclease (Sigma Chemical Co., St. Louis, Mo.), as described by Marmur (6). The DNA was then purified by column chromatography, using Fractogel 65 (BDH, Poole, England) as the column matrix. The DNA base composition was estimated with a Gilford model 240 spectrophotometer and a Gilford model 2527 thermal programmer from its melting temperature in standard saline citrate ( $\mathrm{pH} 7.0)$. DNA from Escherichia coli strain B (Sigma) was used as a reference.

Electron microscopy. The samples for thin sections were stained with tannic acid (13) and prepared as previously described (5). Intact cells were negatively stained with $2 \%$ phosphotungstic acid $(\mathrm{pH} 6.5)$. The micrographs were taken with a model JEM-100B transmission electron microscope at $80 \mathrm{kV}$.

\section{RESULTS}

Bacteriology. All root canal isolates were obligately anaerobic, gram-negative rods that were resistant to kanamycin and vancomycin and susceptible to metronidazole. On Bacteroides bile-esculin medium no growth was observed. Fermentation patterns and other characteristics are shown in Table 1. The biochemical characteristics of strains ES42 and ES57 were almost identical to the characteristics of reference strains of $B$. capillus, B. buccae, B. oris, and $B$. pentosaceus, with only gelatin liquefaction showing variability.

The DNA base compositions and MDH and GDH mobilities of the pentose-fermenting strains with an S-layer are summarized in Table 2.

Electron microscopy. Some strains (B. capillus ATCC $33690^{\mathrm{T}}$ and ATCC $33691, B$. buccae ATCC $33574^{\mathrm{T}}, B$. pentosaceus $\mathrm{NP}_{33}{ }^{\mathrm{T}}$ and WPH61, and Bacteroides sp. strains ES42 and ES57) had a clearly distinguishable S-layer when negatively stained cells were examined (Fig. 1 through 7, arrows). Thin-sectioned cells stained with tannic acid confirmed the presence of an S-layer in all of these strains (Fig. 8 through 14). Tannic acid-stained cells of most strains with an S-layer also had disorganized electron-opaque material outside the S-layer, typical of a slime or capsular layer. The most peripheral layer of the B. buccae cells (Fig. 3 and 10) appeared to be more electron dense than the layer of $B$. capillus and $B$. pentosaceus cells. Long hairlike fibers emerged from the S-layer through the electron-opaque material in all strains except $B$. pentosaceus WPH61 and Bacteroides sp. strain ES57, where such fibers were not

TABLE 2. DNA base composition and MDH and GDH mobilities of pentose-fermenting strains with an S-layer

\begin{tabular}{lccc}
\hline \multicolumn{1}{c}{ Strain } & $\begin{array}{c}\text { Guanine-plus- } \\
\text { cytosine content } \\
\text { (mol\%) }\end{array}$ & \multicolumn{2}{c}{$\begin{array}{c}\text { Enzyme mobil- } \\
\text { ities (cm) }\end{array}$} \\
\cline { 3 - 5 } & & MDH & GDH \\
\hline $\begin{array}{l}\text { B. pentosaceus } \\
\text { NP333 }\end{array}$ & 51 & 3.9 & 4.8 \\
$\quad$ WPH61 & 51 & 3.9 & 4.8 \\
B. capillus & & & \\
ATCC 33690 & 50 & 3.9 & 4.8 \\
ATCC 33691 & 51 & 3.9 & 4.8 \\
B. buccae ATCC 33574 & 50 & 3.9 & 4.8 \\
Bacteroides sp. & & & \\
$\quad$ ES42 & 52 & 4.1 & 4.8 \\
ES57 & 51 & 3.9 & 4.8 \\
\hline
\end{tabular}



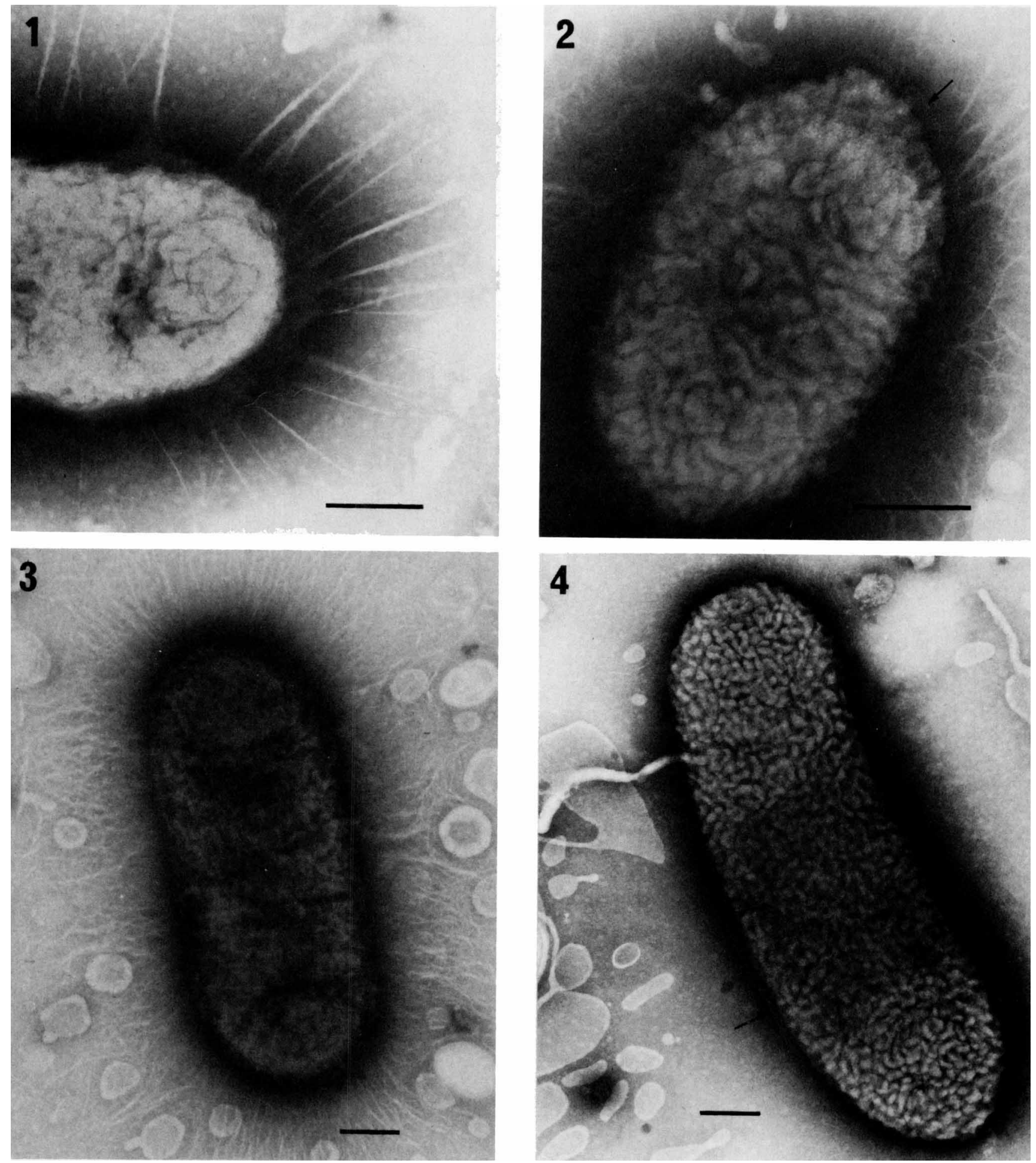

FIG. 1. Negatively stained cell of B. capillus ATCC $33690^{\mathrm{T}}$. Bar $=0.2 \mu \mathrm{m}$.

FIG. 2. Negatively stained cell of $B$. capillus ATCC 33691. The arrow indicates the S-layer. Bar $=0.2 \mu \mathrm{m}$.

FIG. 3. Negatively stained cell of $B$. buccae ATCC $33574^{\mathrm{T}}$. Bar $=0.2 \mu \mathrm{m}$.

FIG. 4. Negatively stained cell of $B$. pentosaceus NP333 ${ }^{\mathrm{T}}$. The arrow indicates the S-layer. Bar $=0.2 \mu \mathrm{m}$. 

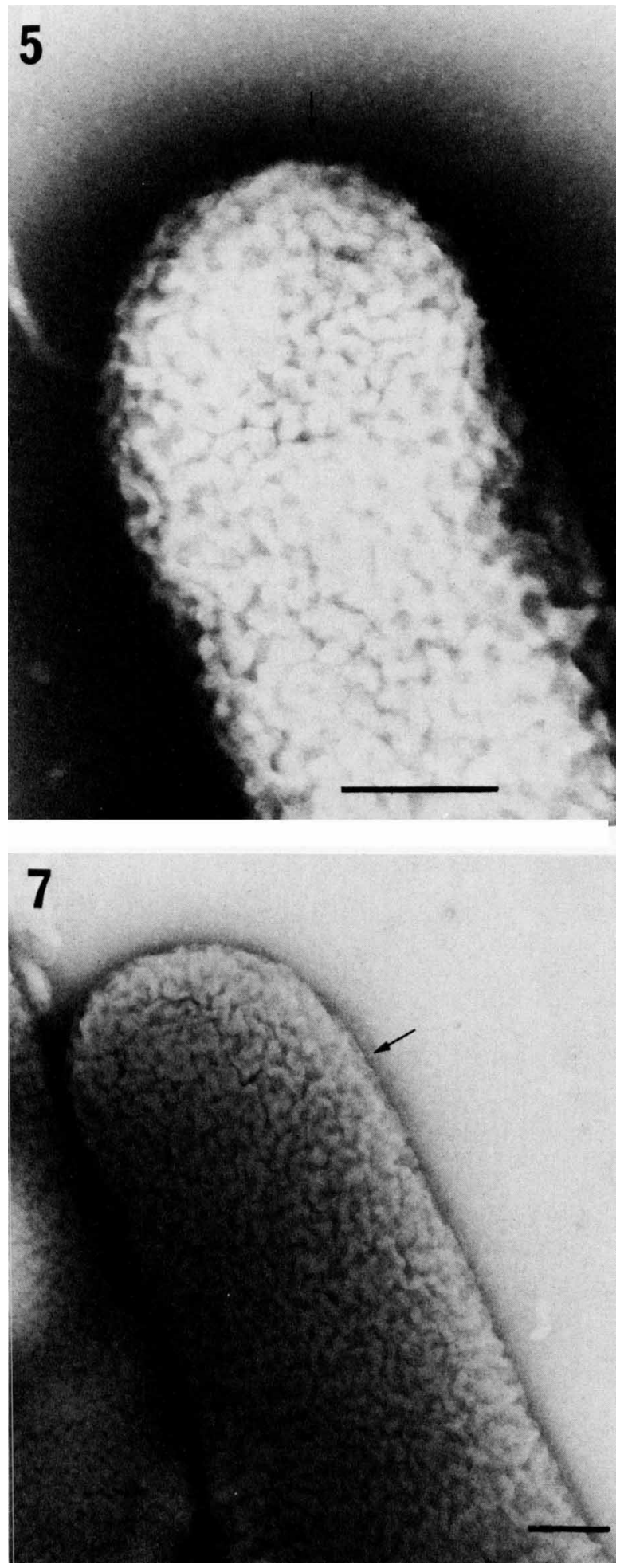

detected even after repeated examination of cells from both MCG and HMCG agar plates (Fig. 12 and 14, respectively).

Neither $B$. oris ATCC $33573^{\mathrm{T}}$ and ATCC 27518 nor the six strains of $B$. oralis and $B$. veroralis (including strains ES2759 and ES2834) had organized structures that suggested the presence of an S-layer outside the outer membrane (Fig. 15 through 18). However, disorganized electron-opaque material was present on the outer surface of the cells.

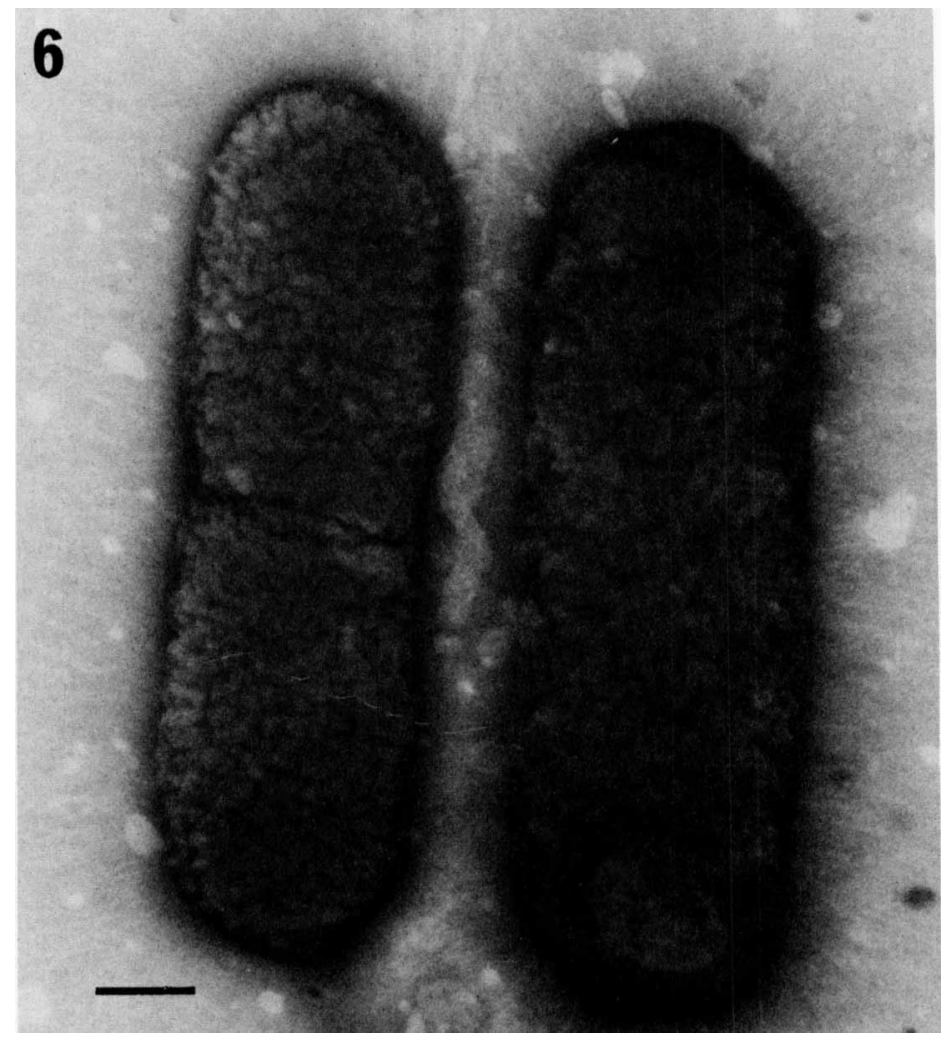

FIG, 5. Negatively stained cell of $B$. pentosaceus WPH61. The arrow indicates the S-layer. $\mathrm{Bar}=0.2 \mu \mathrm{m}$.

FIG. 6. Negatively stained cells of Bacteroides sp. strain ES42. Bar $=0.2 \mu \mathrm{m}$.

FIG. 7. Negatively stained cell of Bacteroides sp. strain ES57. The arrow indicates the S-layer. Bar $=0.2 \mu \mathrm{m}$.

Colonial characteristics. After incubation for 3 days or less on MCG agar plates, the colonies of all strains were light gray. During prolonged incubation (up to 1 week) a light ochre pigment was observed in all pentose-fermenting strains except the $B$. oris strains. On HMCG agar after 7 days of incubation the colonies of both $B$. capillus strains turned dark brown and resembled those of Bacteroides melaninogenicus (11). The strains of $B$. oralis and $B$. veroralis and strains ES2759 and ES2834 produced light reddish brown colonies when they were grown on HMCG agar plates. However, the growth of the bacterial mass was greater with pentose-fermenting strains on both media than with $B$. oralis and $B$. veroralis. The diameters of colonies of $B$. oralis rarely exceeded $1 \mathrm{~mm}$ after 3 days of culture, compared with 2 to $3 \mathrm{~mm}$ for colonies of $B$. veroralis, strains ES2759 and ES2834, and the pentose-fermenting strains. Colonies of $B$. veroralis and $B$. oris were rather flat, whereas colonies of all strains with an S-layer were more convex and higher. Finally, all strains with an S-layer differed from the other strains in that many, but not all, of their colonies possessed an inherent striated structure. The color of the striae differed only slightly from the rest of the colony, but they were readily detected with the naked eye.

\section{DISCUSSION}

Technical developments in electron microscopy, together with new staining methods, have made it possible to apply 

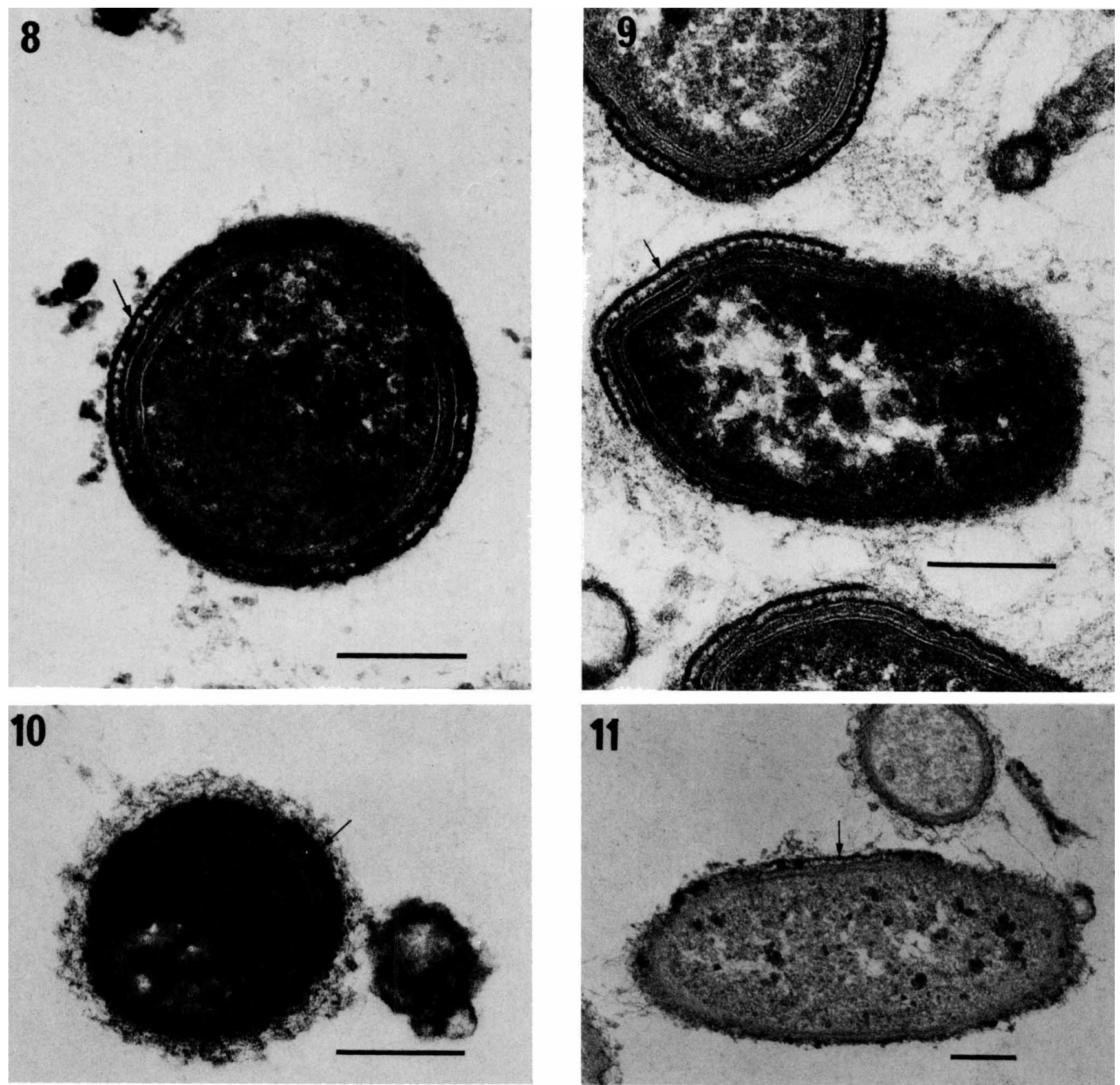

FIG. 8. Thin-sectioned cell of B. capillus ATCC $33690^{\mathrm{T}}$. The arrow indicates the S-layer. Bar $=0.2 \mu \mathrm{m}$.

FIG. 9. Thin-sectioned cells of $B$. capillus ATCC 33691. The arrow indicates the S-layer. Bar $=0.2 \mu \mathrm{m}$.

FIG. 10. Thin-sectioned cell of $B$. buccae ATCC $33574^{\mathrm{T}}$. The arrow indicates the S-layer. Bar $=0.2 \mu \mathrm{m}$.

FIG. 11. Thin-sectioned cell of B. pentosaceus NP333 ${ }^{\mathrm{T}}$. The arrow indicates the S-layer. Bar $=0.2 \mu \mathrm{m}$.

morphological data to modern bacterial systematics (4). Structures such as cell wall components, pili, or flagella, for example, cannot be readily distinguished by conventional (e.g., thin-sectioning) methods. Not only the presence but also the suggestive nature and dimensions of otherwise indistinguishable features are easily demonstrated by electron microscopy. On the other hand, mere morphological similarity is not the decisive factor when the taxonomic definition of a bacterial strain is confirmed. This was demonstrated by Lai et al. (4) with strains of Bacteroides ureolyticus and Bacteroides gracilis.
The presence of an S-layer external to the peptidoglycan layer in gram-positive bacteria and external to the outer membrane in gram-negative bacteria has been well documented in several species $(3,7,12)$. However, of the gram-negative, anaerobic rod-shaped bacteria, only $\mathrm{Bac}$ teroides nodosus, a strain of Campylobacter fetus, and some spirochetes have been shown to possess an S-layer (for a review, see reference 12). Recently, Kornman and Holt (3) described the new species $B$. capillus with an S-layer. Another recently documented species, Wolinella recta, also possesses structurally arranged subunits in the cell envelope 

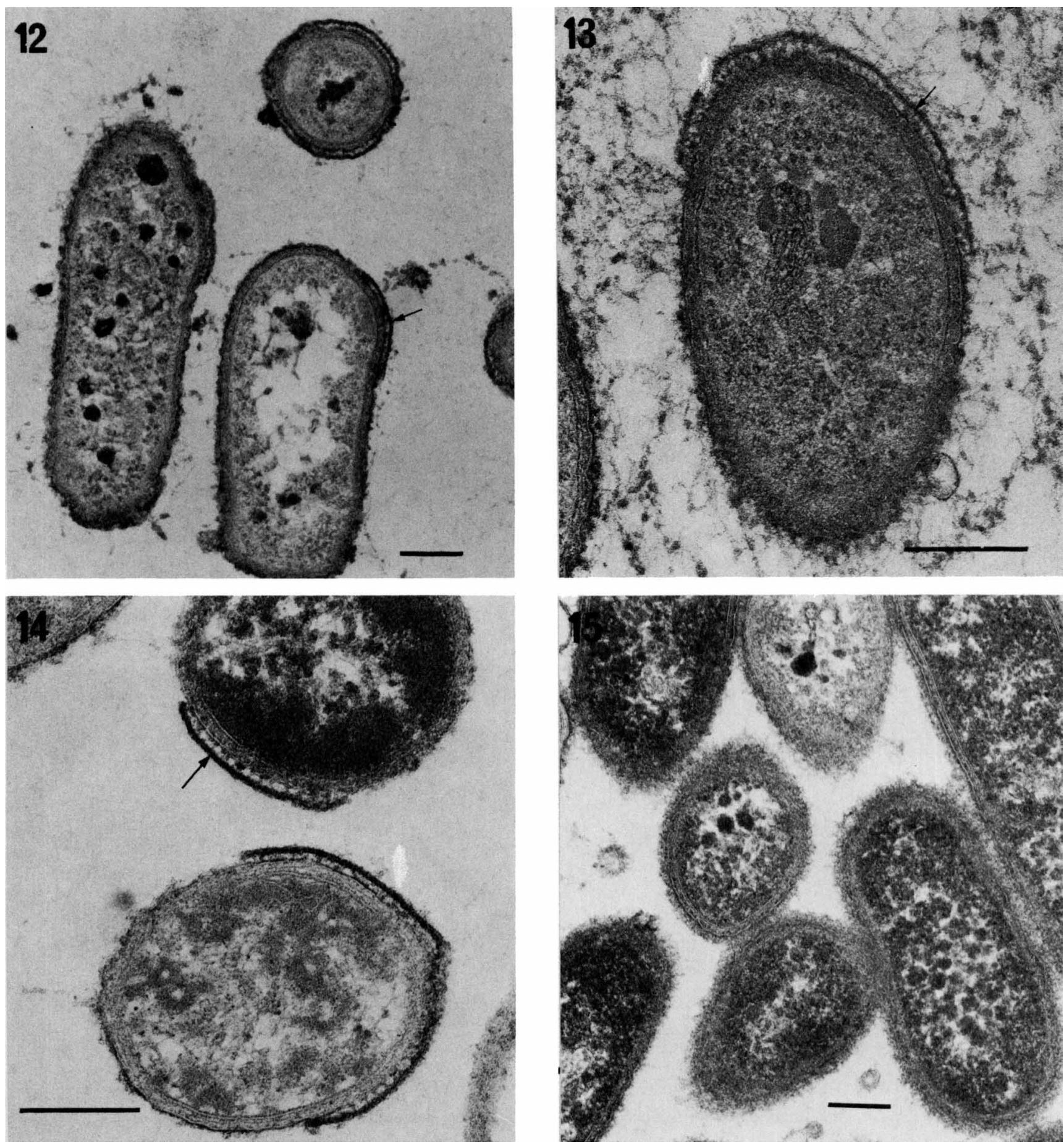

FIG. 12. Thin-sectioned cell of B. pentosaceus NP333' ${ }^{\mathrm{T}}$. The arrow indicates the S-layer. Bar $=0.2 \mu \mathrm{m}$.

FIG. 13. Thin-sectioned cell of Bacteroides sp.strain ES42. The arrow indicates the S-layer. Bar $=0.2 \mu \mathrm{m}$.

FIG. 14. Thin-sectioned cells of Bacteroides sp.strain ES57.The arrow indicates the S-layer. Bar $=0.2 \mu \mathrm{m}$.

FIG. 15. Thin-sectioned cells of B. oris ATCC 27518. Bar $=0.2 \mu \mathrm{m}$.

(4). Of these species, only B. capillus has an S-layer composed apparently of two lattices (3). Sleytr and Messner (12) considered a double S-layer less common than a single $S$-layer. Of the known human pathogens, one strain of Corynebacterium diphtheriae has been shown to possess a double S-layer (12). With the exception of strains of $B$. oris, all of the pentose-fermenting strains which we studied had an S-layer apparently composed of two separate lattices.

It is interesting that colonial pigmentation and other colonial characteristics clearly showed a difference between 

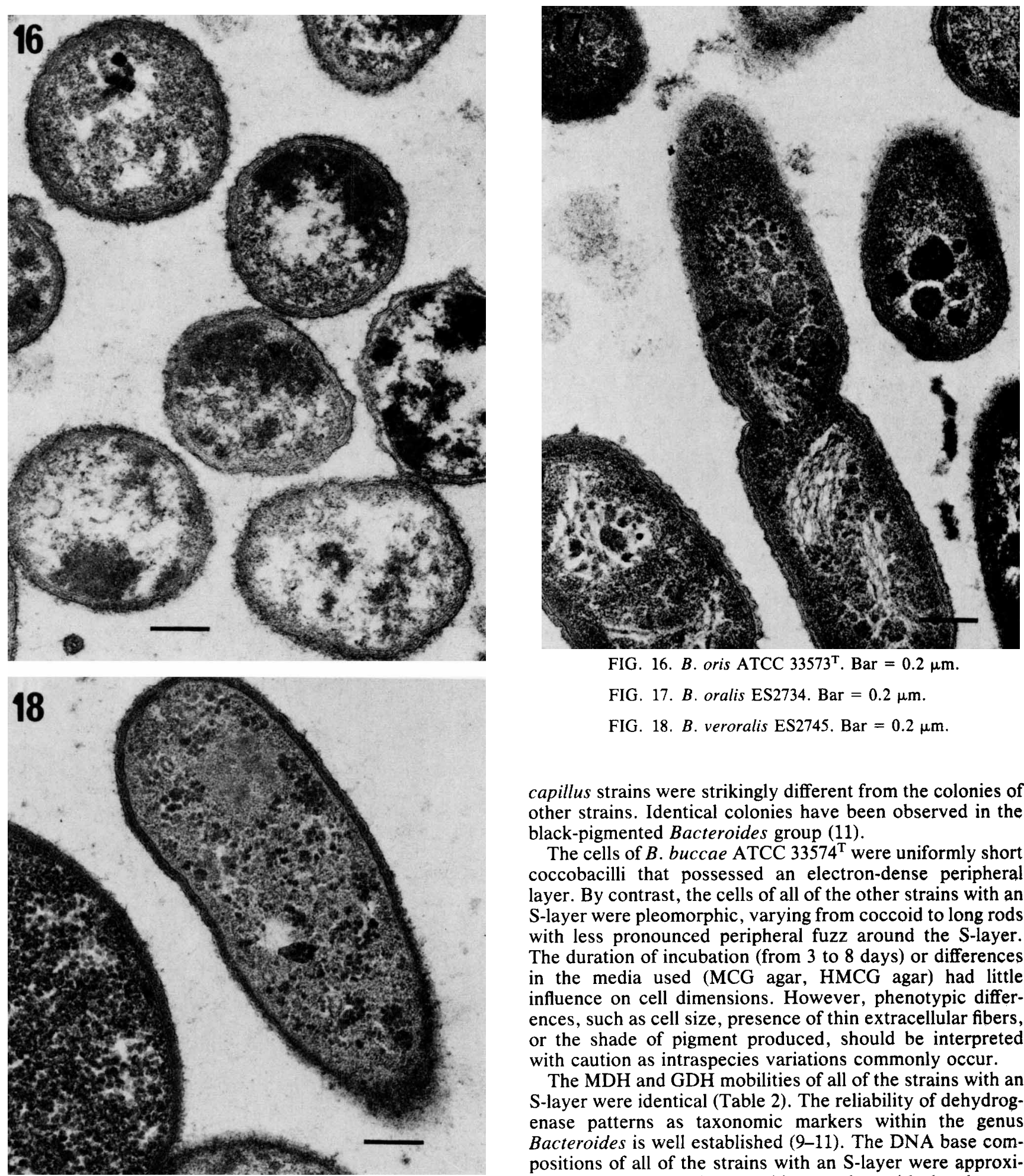

FIG. 16. B. oris ATCC $33573^{\mathrm{T}}$. Bar $=0.2 \mu \mathrm{m}$.

FIG. 17. B. oralis $\mathrm{ES} 2734$. Bar $=0.2 \mu \mathrm{m}$.

FIG. 18. B. veroralis ES2745. Bar $=0.2 \mu \mathrm{m}$.

capillus strains were strikingly different from the colonies of other strains. Identical colonies have been observed in the black-pigmented Bacteroides group (11).

The cells of B. buccae ATCC $33574^{\mathrm{T}}$ were uniformly short coccobacilli that possessed an electron-dense peripheral layer. By contrast, the cells of all of the other strains with an $S$-layer were pleomorphic, varying from coccoid to long rods with less pronounced peripheral fuzz around the S-layer. The duration of incubation (from 3 to 8 days) or differences in the media used (MCG agar, HMCG agar) had little influence on cell dimensions. However, phenotypic differences, such as cell size, presence of thin extracellular fibers, or the shade of pigment produced, should be interpreted with caution as intraspecies variations commonly occur.

The MDH and GDH mobilities of all of the strains with an S-layer were identical (Table 2). The reliability of dehydrogenase patterns as taxonomic markers within the genus Bacteroides is well established (9-11). The DNA base compositions of all of the strains with an S-layer were approximately the same (Table 2). This, together with the electron microscopic observations, emphasizes the homogeneity among B. capillus, B. pentosaceus, B. buccae, and Bacteroides $\mathrm{sp}$. strains ES42 and ES57 and suggests that the oral pentose-fermenting isolates with an S-layer may belong to the same species.

\section{ACKNOWLEDGMENTS} opment of a light brown color on HMCG agar by colonies of
Bacteroides species with an S-layer may be a useful characteristic for screening in addition to striae, which may be best detected on MCG agar plates. After prolonged incubation, the dark brown colonies formed on HMCG agar by both $B$.

the strains with an S-layer and the strains without an S-layer including strains ES2759 and ES2834 (diameter). The development of a light brown color on HMCG agar by colonies of
Bacteroides species with an S-layer may be a useful charac-

We thank Olli-Veikko Renkonen for helpful discussions and Tuire Koro and Kerttu Saarelainen for skillful technical assistance. 
We thank Astra Pharmaceuticals for financial support.

\section{LITERATURE CITED}

1. Benno, Y., T. Watabe, and T. Mitsuoka. 1983. Bacteroides pyogenes sp. nov., Bacteroides suis sp. nov., and Bacteroides helcogenes sp. nov., new species from abscesses and feces of pigs. Syst. Appl. Microbiol. 4:396-407.

2. Holdeman, L. V., W. E. C. Moore, P. J. Churn, and J. L. Johnson. 1982. Bacteroides oris and Bacteroides buccae, new species from human periodontitis and other human infections. Int. J. Syst. Bacteriol. 32:125-131.

3. Kornman, K. S., and S. C. Holt. 1981. Physiological and ultrastructural characterization of a new Bacteroides species (Bacteroides capillus) isolated from severe localized periodontitis. J. Periodontal Res. 16:542-555.

4. Lai, C.-H., M. A. Listgarten, A. C. R. Tanner, and S. S. Socransky. 1981. Ultrastructures of Bacteroides gracilis, Campylobacter concisus, Wolinella recta, and Eikenella corrodens, all from humans with periodontal disease. Int. J. Syst. Bacteriol. 31:465-475.

5. Lounatmaa, K., P. H. Mäkelä, and M. Sarvas. 1976. Effect of polymyxin on the ultrastructure of the outer membrane of wild-type and polymyxin-resistant strains of Salmonella. J. Bacteriol. 127:1400-1407.

6. Marmur, J. 1961. A proceduie for the isolation of deoxyribonucleic acid from micro-organisms. J. Mol. Biol. 3:208-218.
7. Ranta, H., K. Lounatmaa, M. Haapasalo, and K. Ranta. 1983.Isolation and ultrastructure of Bacteroides sp. with external cellwall layer (S-layer) in periapical osteitis. Scand. J. Dent. Res. 91:458-464.

8. Shah, H. N., and M. D. Collins. 1981. Bacteroides buccalis, sp. nov., Bacteroides denticola, sp. nov., and Bacteroides pentosaceus, sp. nov., new species of the genus Bacteroides from the oral cavity. Zentralbl. Bakteriol. Parasitenkd. Infektionskr. Hyg. Abt. 1 Orig. Reihe C 2:235-241.

9. Shah, H. N., and M. D. Collins. 1983. Genus Bacteroides, a chemotaxonomical perspective. J. Appl. Bacteriol. 55:403-416.

10. Shah, H. N., and R. A. D. Williams. 1982. Dehydrogenase patterns in the taxonomy of Bacteroides. J. Gen. Microbiol. 128:2955-2965.

11. Shah, H. N., R. A. D. Williams, G. H. Bowden, and J. M. Hardie. 1976. Comparison of the biochemical properties of Bacteroides melaninogenicus from human dental plaque and other sites. J. Appl. Bacteriol. 55:151-158.

12. Sleytr, U. B., and P. Messner. 1983. Crystalline surface layers on bacteria. Annu. Rev. Microbiol. 37:311-339.

13. Wagner, R. C. 1976. Effect of tannic acid on electron images of capillary endothelial cell membranes. J. Ultrastruct. Res. 57:132-139.

14. Watabe, J., Y. Benno, and T. Mitsuoka. 1983. Taxonomic study of Bacteroides oralis and related organisms and proposal of Bacteroides veroralis sp. nov. Int. J. Syst. Bacteriol. 33:57-64. 